\title{
Reologia de concretos refratários na presença de diferentes tipos de aditivo e ligante hidráulico
}

\section{(Refractory castables rheology in the presence of different sort of additive and hydraulic binders)}

\author{
I. R. Oliveira, V. C. Pandolfelli \\ Departamento de Engenharia de Materiais - DEMa, Universidade Federal de S. Carlos - UFSCar \\ Rod. Washington Luiz, km 235, C.P. 676, S. Carlos, SP 13565-905 \\ ivone@iris.ufscar.br,vicpando@power.ufscar.br
}

\begin{abstract}
Resumo
Aditivos químicos podem ser adicionados aos concretos refratários com diferentes propósitos, como por exemplo, visando a dispersão das partículas finas da matriz por meio de mecanismos de dispersão eletrostáticos/eletroestéricos (dispersantes) e para controlar o processo de hidratação das partículas do agente ligante (retardadores/aceleradores). O estado de dispersão da matriz de um concreto refratário apresenta uma grande influência no comportamento reológico desse material, determinando as técnicas utilizadas para a sua aplicação. Os concretos bombeáveis tem crescido em importância tecnológica devido principalmente à possibilidade de se moldar peças que se encontram distantes do local de mistura, de maneira rápida, eficiente, sem desperdícios e com menor custo. Todavia, para que as vantagens tecnológicas deste processo sejam melhor exploradas, é necessário que o comportamento reológico e as características de endurecimento (tempo de pega) do concreto sejam compatíveis com o processo. Neste contexto, este trabalho teve como objetivo avaliar simultaneamente a capacidade de diferentes aditivos quanto à dispersão das partículas da matriz, bem como a sua influência no processo de hidratação de diferentes tipos de ligantes hidráulicos, utilizando-se medidas da fluidez e da trabalhabilidade destes concretos refratários.
\end{abstract}

Palavras-chave: alumina hidratável, aluminato de cálcio, concretos refratários, fluidez, trabalhabilidade.

Abstract

Chemical additives may be added to the castables for different purposes, as for example, to disperse matrix fine particles through electrostatic/electrosteric mechanisms (dispersants) and to control the hydration process of cement particles (retarders/accelerators). The state of dispersion of the castables matrix particles presents a direct influence in their rheological behavior, defyning the techniques that can be used for their installation. The growing demand for automatically transported refractory castables has stimulated the use of pumpable castables due to its fast and high quality placing, without losses and with reduced costs. However, in order to explore the technological advantages of this process it is necessary that the rheological behavior and setting characteristics of castables are in tune with the process. In this context, the objective of this work was simultaneously evaluate the influence of the different additives on the matrix particles dispersion and the hydration process of different hydraulic binder, through fluidity and setting time measurements of refractory castables.

Keywords: hydratable alumina, calcium aluminate cement, refractory castables, fluidity, workability.

\section{INTRODUÇÃO}

Concretos refratários usados nas indústrias de aço e outras aplicações envolvendo alta temperatura são tipicamente constituídos por uma mistura de matérias-primas grosseiras $(5 \mathrm{~mm}-100 \mu \mathrm{m})$ e finas $(100-0,1 \mu \mathrm{m})$, um agente ligante $\mathrm{e}$ aditivos químicos em água.

Os agentes ligantes são em sua maioria, óxidos capazes de se hidratar e promover a coesão do corpo conformado. Nesta categoria podem ser incluídos os cimentos de alta alumina e as aluminas hidratáveis.

Os cimentos de alta alumina (cimentos de aluminato de cálcio, CAC) constituem os agentes ligantes mais utilizados em aplicações industriais, devido principalmente a sua disponibilidade, baixo custo, capacidade de conferir alta resistência mecânica a verde aos concretos e resistência ao ataque de agentes agressivos, quando em uso [1]. Já, as aluminas hidratáveis foram desenvolvidas como alternativa direta ao uso de cimentos refratários, uma vez que o óxido de cálcio oriundo do cimento leva a uma deterioração das propriedades mecânicas dos concretos a altas temperaturas em sistemas contendo sílica. Tais ligantes hidráulicos podem ser compostos por uma variedade de fases de transição da alumina. São geralmente produzidos pela calcinação rápida da gibsita, resultando principalmente na alumina-rho ( $\rho)$, que apresenta baixa cristalinidade e alta área superficial.

Os aditivos químicos podem ser adicionados aos concretos com diferentes propósitos, como por exemplo: a) 
promover a dispersão das partículas finas da matriz por meio de mecanismos de dispersão eletrostáticos/eletroestéricos (dispersantes), b) melhorar a capacidade de molhamento de algumas matérias-primas em água (surfactantes) e c) controlar o processo de hidratação das partículas do agente ligante (retardadores/aceleradores).

Dessa forma, a seleção de aditivos químicos apresenta um forte impacto nas várias características do processamento dos concretos, incluindo o estado de dispersão das partículas, homogeneidade, propriedades reológicas, comportamento de "pega" e consumo de água.

O estado de dispersão das partículas do concreto determina a fluidez desses materiais enquanto sua trabalhabilidade é governada principalmente pelo processo de hidratação do agente ligante [2].

O processo de hidratação das partículas de cimento em água envolve três períodos distintos: dissolução de íons, nucleação e precipitação de fases hidratadas. Tão $\operatorname{logo}$ as partículas de cimento entram em contato com a água, fases anidras de aluminato de cálcio começam a dissociar e liberam íons cálcio $\left(\mathrm{Ca}^{2+}\right)$ e tetra hidróxido aluminato $\left(\mathrm{Al}(\mathrm{OH})_{4}^{-}\right)$ no meio líquido. $\mathrm{O}$ processo de dissolução ocorre até que a concentração desses íons na solução aquosa alcance um certo nível de saturação, promovendo a sua precipitação na forma de hidratos de aluminato de cálcio, por meio de mecanismos de nucleação e crescimento. A precipitação dos primeiros produtos hidratados diminui a concentração de íons em solução para níveis abaixo da condição de saturação, favorecendo a dissociação de fases anidras. Isso resulta num processo contínuo de dissolução-precipitação que ocorre até que a maioria (ou toda) fase anidra tenha reagido. Desde que a nucleação heterogênea na superfície das partículas seja favorecida, as fases hidratadas precipitadas tendem a formar fortes ligações entre partículas vizinhas, promovendo o endurecimento ou pega do concreto $[3,4]$.

A capacidade ligante das aluminas hidratáveis deriva da sua fácil rehidratação quando em contato com a água a temperatura ambiente [5]:

$$
\rho-\mathrm{Al}_{2} \mathrm{O}_{3}+\mathrm{H}_{2} \mathrm{O} \rightarrow \mathrm{Al}_{2} \mathrm{O}_{3} \cdot 3 \mathrm{H}_{2} \mathrm{O}+\mathrm{Al}_{2} \mathrm{O}_{3}(1 \approx 2) \mathrm{H}_{2} \mathrm{O}
$$

Nos primeiros estágios da hidratação uma espessa camada de alumina gel é formada e, com o decorrer da reação, parte deste gel é transformado em boemita $\left(\mathrm{Al}_{2} \mathrm{O}_{3} 1 \approx 2 \mathrm{H}_{2} \mathrm{O}\right)$ e principalmente baierita $\left(\mathrm{Al}_{2} \mathrm{O}_{3} 3 \mathrm{H}_{2} \mathrm{O}\right)$. Os cristais interligados de baierita e o gel conferem resistência mecânica a verde aos refratários por meio do preenchimento de poros e redução dos defeitos superficiais. Tal cristalização também favorece a formação de estruturas na superfície dos agregados, unindo os grãos adjacentes à matriz circundante [6].

Têm-se observado que o processo de hidratação do ligante em meio aquoso é sensivelmente influenciado pela presença de aditivos dispersantes [7-9]. Neste contexto, este trabalho teve como objetivo avaliar simultaneamente a capacidade de diferentes aditivos quanto à dispersão das partículas da matriz, bem como a sua influência no processo de hidratação de diferentes tipos de ligantes hidráulicos, por meio de medidas de fluidez e trabalhabilidade de concretos refratários.

\section{MATERIAIS E MÉTODOS}

Os concretos refratários foram formulados segundo o modelo de empacotamento de partículas de Andreasen [10], com coeficiente (q) 0,21 e diâmetro máximo de partícula igual a $4750 \mu \mathrm{m}$, por meio do software PSDesigner [11]. Como agentes ligantes foram utilizados a alumina hidratável Alphabond 300 (Almatis-US) e os cimentos de aluminato de cálcio CA14M(Almatis-US) e Secar 71 (Lafarge AluminatesFrança). A caracterização das matérias-primas e ligantes, bem como as composições resultantes são apresentadas nas Tabelas I e II, respectivamente.

Como aditivos dispersantes foram avaliados os seguintes compostos: ácido cítrico anidro (Labsynth, $192 \mathrm{~g} / \mathrm{mol}$ ), citrato de diamônio (Sigma Aldrich) e os polímeros da família do poliglicol, fornecidos pela Bayer (CD, CT e CS). Esses aditivos foram adicionados ao concreto com teores

Tabela I - Caracterização das matérias-primas e ligantes selecionados para formulação dos concretos refratários. [Table I - Characterization of raw materials and binders used for the preparation of the refractory castables.]

\begin{tabular}{ccccc}
\hline \multicolumn{2}{c}{ Matérias-primas } & $\begin{array}{c}\text { Distribuição } \\
\text { granulométrica }(\mu \mathrm{m})\end{array}$ & $\begin{array}{c}\text { Densidade real } \\
\left(\mathrm{g} / \mathrm{cm}^{3}\right)\end{array}$ & $\begin{array}{c}\text { Área } \\
\text { superficial }\left(\mathrm{m}^{2} / \mathrm{g}\right)\end{array}$ \\
\hline Alumina & $4 / 10$ & $4750-2000$ & 3,90 & - \\
eletrofundida & $8 / 20$ & $2360-710$ & 3,90 & - \\
branca & $20 / 40$ & $710-355$ & 3,90 & - \\
(agregados) & $40 \mathrm{~F}$ & $425-106$ & 3,90 & - \\
& $200 \mathrm{~F}$ & $106-11,3$ & 3,90 & - \\
Alumina calcinada & A 17NE & $11,30-0,21$ & 3,94 & 2,90 \\
(matriz) & CT 3000SG & $6,69-0,21$ & 3,97 & 8,00 \\
& CA14M & $63-5,6$ & 2,96 & 1,87 \\
Ligantes & Secar 71 & $63-8,0$ & 2,98 & 1,17 \\
& Alphabond 300 & $9,5-0,18$ & 3,20 & 162,43 \\
\hline
\end{tabular}


Tabela II - Composições dos concretos refratários preparados com diferentes tipos de ligantes.

[Table II - Refractory castables compositions prepared with different sources of binders.]

\begin{tabular}{cccc}
\hline & \multicolumn{3}{c}{ Tipo de ligante } \\
$\begin{array}{c}\text { Matérias- } \\
\text { primas }(\%-p)\end{array}$ & CA14M & Secar 71 & Alphabond \\
\hline Agregado & 69 & 69 & 75 \\
$(4 / 10-200 \mathrm{~F})$ & & & \\
CT 3000SG & 3,00 & 3,00 & 5,00 \\
A 17NE & 22,00 & 22,00 & 14,00 \\
CA14M & 6,00 & - & - \\
Secar 71 & - & 6,00 & - \\
Alphabond 300 & - & - & 6,00 \\
\hline
\end{tabular}

previamente determinados por meio de curvas de dispersão realizadas para suspensões aquosas da matriz e ligantes, isoladamente.

As suspensões aquosas da matriz (A17-NE) e ligantes utilizados foram preparadas com teores de sólidos distintos dados as diferentes distribuições granulométricas e estado de aglomeração das partículas: 57\%-vol. (A17-NE), 40\%vol. (CA14M, Secar-71) e 20\%-vol. (Alphabond 300). Esses ensaios consistiram na medida da viscosidade das suspensões em função do teor de dispersante para uma taxa de cisalhamento de $50 \mathrm{~s}^{-1}$, utilizando-se o equipamento Rheostress 300 da ThermoHaake. Adicionalmente, foram realizadas medidas de potencial de zeta para suspensões da matriz (A17-NE) na presença dos diferentes aditivos. As medidas de potencial zeta foram monitoradas em função do $\mathrm{pH}$, com o auxílio de um sensor conectado a um sistema automático de aquisição de dados (ESA 9800, Matec Applied Sciences - UK). Soluções aquosas de KOH e $\mathrm{HNO}_{3}(2 \mathrm{~N})$ foram utilizadas para ajustar o $\mathrm{pH}$ das suspensões.

A mistura das matérias-primas, após pesagem das composições formuladas, foi realizada em um reômetro para concretos [12] com rotação constante de $44 \mathrm{rpm}$. Inicialmente foram realizados ensaios exploratórios de mistura nos quais foram ajustados os teores de água e aditivo necessários para a preparação dos concretos.

A adição do teor de água definido para cada tipo de composição foi realizada em etapas para garantir a efetiva mistura dos sistemas otimizando a fluidez [13, 14]. Após mistura a seco durante 60 segundos visando a quebra dos aglomerados e conseqüente homogeneização de seus componentes, adicionou-se $75 \%$ do total de água necessária para a "virada do concreto", a qual pode ser definida como o momento no qual o concreto passa a se comportar como um meio contínuo. Ao "virar", o restante da água foi adicionado e a rotação foi mantida até a completa mistura do sistema.

Após este processo de mistura, os concretos foram analisados quanto a fluidez livre e perfil de endurecimento. $\mathrm{O}$ teste de fluidez livre consiste em preencher um molde cônico com o concreto e retirá-lo verticalmente para possibilitar o escoamento do material. A medida de fluidez livre corresponde ao espalhamento porcentual médio formado pelo concreto obtido utilizando-se um molde no formato de tronco de cone. Já para a avaliação quanto ao perfil de endurecimento a mistura dos concretos foi mantida a uma rotação constante de $20 \mathrm{rpm}$ até que fosse registrado aumento do nível de torque (curvas de torque em função do tempo). O tempo após a virada no qual se verificou o início do aumento de torque foi tomado como o tempo de trabalhabilidade do sistema.

\section{RESULTADOS E DISCUSSÃO}

Inicialmente, suspensões aquosas da matriz (A17-NE) e dos ligantes utilizados foram preparadas isoladamente para avaliação quanto à eficiência de diferentes aditivos na dispersão das partículas desses materiais. Os resultados do teor necessário para promover a menor viscosidade da suspensão em cada caso são apresentados na Tabela III.

Suspensões da matriz também foram avaliadas quanto ao desenvolvimento de carga elétrica na superfície das partículas na presença do teor ótimo dos aditivos testados $\left(0,1 \mathrm{mg} / \mathrm{m}^{2}\right)$. As curvas de potencial zeta em função do $\mathrm{pH}$ são apresentadas na Fig. 1. Entre os aditivos testados, o ácido cítrico e o citrato promoveram maior potencial de repulsão entre as partículas da matriz justificando os menores valores de viscosidade obtidos.

Tabela III - Viscosidades mínimas obtidas para suspensões de A17-NE (57\%-volume), Alphabond 300 (20\%-volume), CA14M e Secar-71 (40\%-volume) na presença de um teor ótimo de aditivo.

[Table III - Viscosity measurements of suspensions containing, A17-NE (57 vol\%), Alphabond 300 (20 vol\%), CA14M and Secar-71 (40 vol\%), prepared with optimum additive content.]

\begin{tabular}{|c|c|c|c|c|c|}
\hline \multirow{2}{*}{ Aditivos } & \multirow{2}{*}{$\begin{array}{c}\text { Teor } \\
\text { ótimo } \\
\left(\mathrm{mg} / \mathrm{m}^{2}\right)\end{array}$} & \multicolumn{4}{|c|}{$\begin{array}{c}\text { Materiais } \\
\text { viscosidades mínimas (mPa.s), } 50 \mathrm{~s}^{-1}\end{array}$} \\
\hline & & 17-NE & $\begin{array}{l}\text { Alphabond } \\
300\end{array}$ & CA14M & Secar-71 \\
\hline \multirow[t]{2}{*}{$\mathrm{s} /$ aditivo } & 0 & 852 & 154 & 386 & 473 \\
\hline & 0,1 & 190 & & & \\
\hline \multirow{2}{*}{$\begin{array}{l}\text { Ácido } \\
\text { cítrico }\end{array}$} & 0,2 & & 4 & & \\
\hline & 0,7 & & & 281 & 310 \\
\hline \multirow{2}{*}{$\begin{array}{l}\text { Citrato } \\
\text { diamônio }\end{array}$} & 0,1 & 192 & 4 & & \\
\hline & 0,6 & & & 320 & 299 \\
\hline \multirow{3}{*}{$\mathrm{CD}$} & 0,1 & 279 & & & \\
\hline & 0,3 & & 6 & & \\
\hline & 1,5 & & & 102 & 66 \\
\hline \multirow{3}{*}{$\mathrm{CT}$} & 0,1 & 381 & & & \\
\hline & 0,2 & & 9 & & \\
\hline & 0,9 & & & 83 & 73 \\
\hline \multirow{3}{*}{$\mathrm{CS}$} & 0,1 & 320 & & & \\
\hline & 0,2 & & 20 & & \\
\hline & 0,9 & & & 119 & 57 \\
\hline
\end{tabular}




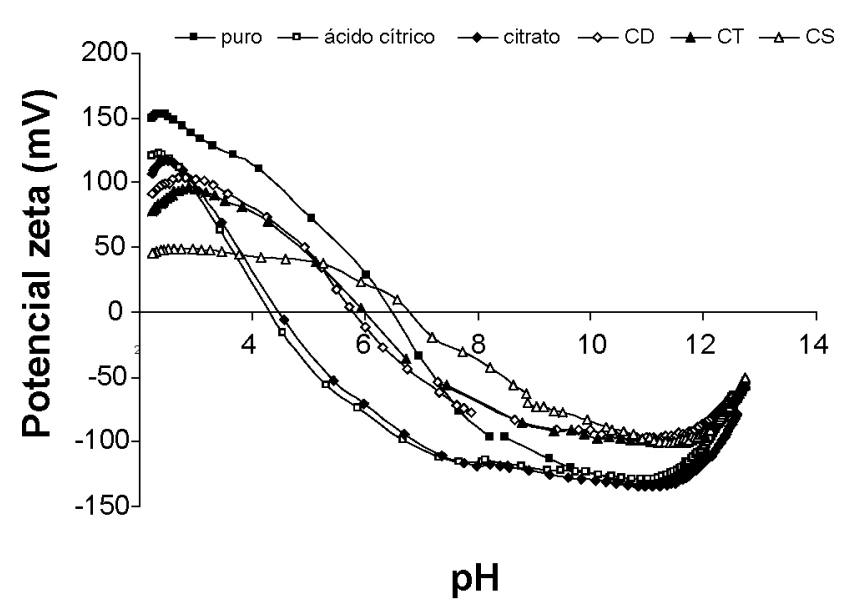

Figura 1: Curvas de potencial zeta em função do $\mathrm{pH}$ para suspensões de alumina A17-NE na presença de um teor ótimo dos diferentes aditivos testados $\left(0,1 \mathrm{mg} / \mathrm{m}^{2}\right)$.

[Figure 1: Zeta potential curves as a function $\mathrm{pH}$ for alumina suspensions (A17-NE) containing $0.1 \mathrm{mg} / \mathrm{m}^{2}$ of different additives.]

Uma vez conhecido o efeito dos aditivos sobre cada material (matriz e ligante) isoladamente, foi testada a sua eficiência na dispersão do concreto refratário. Os concretos refratários podem ser visualizados como uma suspensão aquosa com alta concentração de sólidos, onde a adequada dispersão da matriz possibilita a obtenção de superiores valores de fluidez [15]. Para cada composição testada o teor de aditivo foi variado do valor necessário para a dispersão da matriz $\left(0,1 \mathrm{mg} / \mathrm{m}^{2}\right)$ até o teor determinado para cada ligante específico. O teor ótimo para cada caso, que permitiu a preparação de concretos homogêneos bem como o teor de água utilizado são apresentados na Tabela IV. Nota-se que para os ligantes CA14M e Secar-71 foi necessária uma adição de aditivo bem superior à necessária apenas para a dispersão

Tabela IV - Teores de aditivos e de água determinados para a preparação das diferentes composições dos concretos refratários.

[Table IV-Additive and water content used for the preparation of the different compositions of refractory castables.]

\begin{tabular}{cccc}
\hline Composição & $\begin{array}{c}\text { Tipo de } \\
\text { aditivo }\end{array}$ & $\begin{array}{c}\text { Teor de } \\
\text { aditivo } \\
\left(\mathrm{mg} / \mathrm{m}^{2}\right)\end{array}$ & $\begin{array}{c}\text { Teor de } \\
\text { água } \\
(\%-\mathrm{p})\end{array}$ \\
\hline \multirow{4}{*}{ CA14M ou } & Ácido cítrico & 0,7 & 5,5 \\
Secar 71 & CD & 1,3 & 5,3 \\
& CT & 0,9 & 4,5 \\
& CS & 0,9 & 4,5 \\
\hline \multirow{3}{*}{ Alphabond 300 diamônio } & 0,5 & 6,0 \\
& Ácido cítrico & 0,2 & 6,0 \\
& Citrato diamônio & 0,2 & 6,3 \\
& CD & 0,2 & 5,5 \\
& CT & 0,2 & 5,5 \\
& CS & 0,2 & 5,5 \\
\hline
\end{tabular}

da matriz, atribuindo à adequada dispersão do ligante um papel primordial na otimização de todo o sistema.

O comportamento de mistura de concretos preparados com o ligante CA14M na presença de diferentes aditivos é apresentado na Fig. 2.

Com a adição inicial de água ocorre na mistura, a formação de um filme líquido na superfície das partículas. Devido ao empacotamento, a proximidade desses filmes de partículas distintas causa o surgimento de forças de adesão entre elas devido a efeitos de capilaridade. À medida que mais água é adicionada e/ou que esta esteja mais bem distribuída no sistema, aumenta a quantidade de partículas recobertas, causando aumento no torque necessário para o cisalhamento. Quando o teor de água atinge um determinado valor crítico capaz de formar pontes entre as partículas, ocorre um drástico aumento na resistência ao cisalhamento devido a forças capilares de atração. O teor crítico é atingido quando houver água suficiente para preencher os vazios entre as partículas e recobrir suas superfícies (torque de virada). A partir desta condição, a adição de água ao material provoca o desaparecimento das pontes e a resistência ao cisalhamento diminui instantaneamente ("virada do concreto") $[13,14]$.

Com base nos resultados apresentados na Fig. 2, o aditivo $\mathrm{CD}$ mostrou-se o mais eficiente promovendo a mistura do concreto com inferior valor de torque de virada e um menor tempo necessário para a completa mistura. Menores níveis de torque de virada estão associados a uma melhor dispersão das partículas, uma vez que o concreto adequadamente disperso oferece menor resistência ao cisalhamento, reduzindo o torque necessário para misturá-lo em uma determinada rotação. Além disso, na presença desse aditivo pode-se aliar uma alta fluidez (100\%) com adequado tempo de trabalhabilidade (30 min), como apresentado na Fig. 3. Tais propriedades reológicas do concreto são fundamentais para que sejam determinadas as suas características de aplicação. A obtenção de composições com elevada fluidez facilita a etapa de aplicação do concreto [10, 15, 16]. Fluidos auto-escoantes preenchem moldes por ação do próprio peso enquanto concretos menos fluidos necessitam de técnicas que envolvem vibração de alta energia. Entretanto, a aplicação dos concretos não envolve apenas a sua moldagem, mas também a forma de transporte do material até o local onde será aplicado. Diversas técnicas com este fim podem ser citadas, como a projeção, o vertimento e o bombeamento.

A técnica de bombeamento tem crescido em importância tecnológica na aplicação de concretos, devido principalmente à possibilidade de se moldar peças que se encontram distantes do local de mistura, de maneira rápida, eficiente, sem desperdícios e com menor custo. Neste processo o concreto é bombeado a altas taxas de cisalhamento por meio de uma tubulação, diretamente do misturador até o local de aplicação. Todavia, para que as vantagens tecnológicas deste processo sejam exploradas de maneira ótima, é necessário que o comportamento reológico e as características de endurecimento (tempo de pega) do concreto sejam compatíveis com o processo. No caso de um endurecimento rápido o transporte do concreto em uma tubulação será 


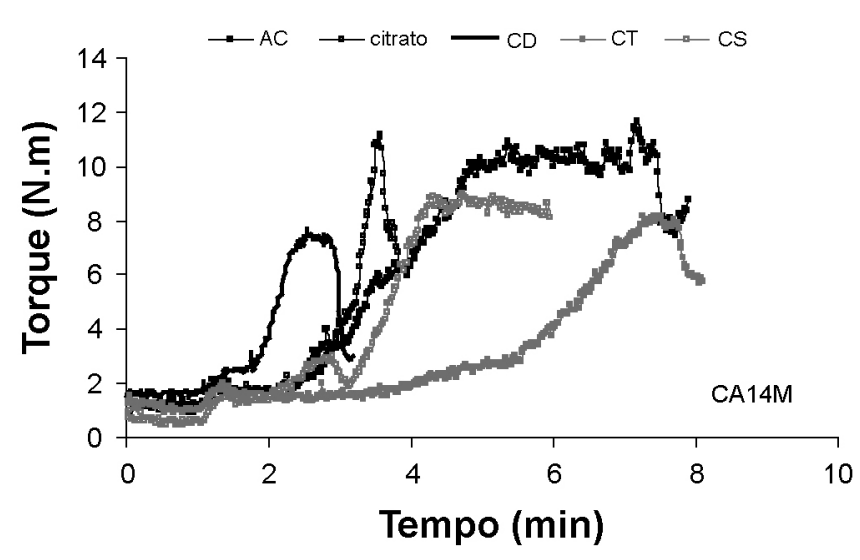

Figura 2: Comportamento de mistura de concretos preparados com CA14M na presença de diferentes aditivos dispersantes.

[Figure 2: Mixing curve profiles for the CA14M containing castables in the presence of different dispersant additives.]

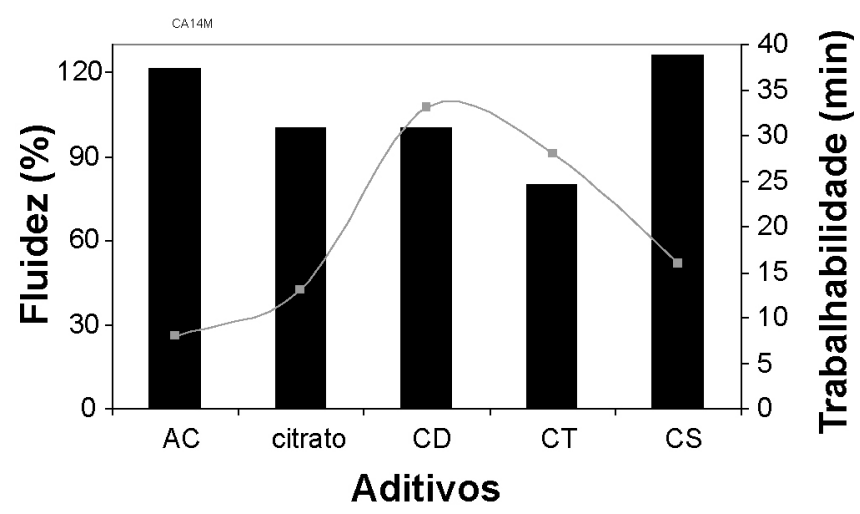

Figura 3: Fluidez e Trabalhabilidade de concretos preparados com CA14M na presença de diferentes aditivos dispersantes.

[Figure 3: Fluidity and workability for the CA14M containing castables in the presence of different dispersant additives.]

limitado, aumentando o risco de entupimento. Dessa forma, um dos principais fatores a ser considerado na adequação da aplicação do concreto refratário é o tempo de endurecimento (trabalhabilidade).

A trabalhabilidade do concreto é primariamente determinada pela velocidade em que ocorrem as reações de hidratação do ligante. $\mathrm{Na}$ presença dos aditivos $\mathrm{AC}$ e CS embora tenham sido obtidos os maiores valores de fluidez indicando a dispersão mais eficiente do concreto, foi observado redução do tempo de trabalhabilidade. Isso pode ser atribuído a pega do concreto ter sido acentuada na presença desses aditivos, ou seja, na presença desses aditivos o mecanismo de hidratação do ligante foi favorecido. O mecanismo de hidratação dos ligantes CA14M e Secar 71, principalmente a etapa de precipitação, pode ser acelerado devido a liberação de cátions no meio líquido por parte dos aditivos. $\mathrm{O}$ aumento da concentração de cátions no meio promove a formação de compostos com os íons $\mathrm{Al}(\mathrm{OH})_{4}^{-}$ provenientes da dissolução das partículas de cimento. Com isso, ocorre um aumento da concentração de íons $\mathrm{Ca}^{2+}$ no meio favorecendo a formação de hidratos mais ricos em cálcio que são por natureza menos solúveis e portanto, precipitam mais rapidamente, acelerando a pega do concreto.

Entretanto, o aditivo AC bem como o citrato são apontados na literatura $[8,9,17]$ como eficientes aditivos retardadores do mecanismo de hidratação. Tal comportamento foi confirmado em ensaios anteriores nos quais o tempo de pega de ligantes distintos foram medidos na presença de diferentes aditivos dispersantes [8,9]. Tais aditivos apresentam grande afinidade pelos íons cálcio e assim dificultam a formação de hidratos menos solúveis atrasando a etapa de precipitação. Com isso, tudo indica que a "pega" inicial do concreto responsável pelo aumento do torque (queda de trabalhabilidade) não é causada pela formação de hidratos quando na presença desses aditivos.

Um outro fator a ser considerado é a conseqüência do aumento da força iônica resultante da dissolução das partículas do ligante no estado de dispersão das partículas da matriz. Tais aditivos dispersam as partículas da matriz por meio do mecanismo eletrostático de estabilização, ou seja, adsorvem na superfície dessas partículas e promovem repulsão entre elas pela geração de cargas elétricas oriundas da dissociação de alguns dos seus grupos como $\mathrm{OH}$ e $\mathrm{COOH}$, resultando em valores mais negativos de potencial zeta, Fig. 1 . O fato desses grupos ionizados $\left(\mathrm{O}^{-}, \mathrm{COO}^{-}\right)$na superfície dessas partículas serem neutralizados pelos íons $\mathrm{Ca}^{2+}$, provenientes da dissolução do ligante, reduz o potencial de repulsão entre as partículas da matriz promovendo uma aglomeração do sistema. Tal fato justifica a reduzida trabalhabilidade dos concretos quando na presença desses aditivos apesar do eficiente efeito dispersante (altos valores de fluidez, Fig. 3) contrariando também o seu efeito retardador. Em outras palavras, a afinidade desses aditivos quando no meio líquido pelos íons cálcio promove um aumento da dissolução das partículas de cimento gerando um aumento da força iônica do meio. $\mathrm{O}$ aumento da força iônica resulta na compressão da dupla camada elétrica das partículas da matriz, reduzindo a repulsão eletrostática entre as mesmas e tornando-as mais susceptíveis a aglomeração. Além disso, quando a matriz é dispersa com ácido cítrico ou citrato, devido a baixa massa molecular, a camada eletrostática gerada é pouco espessa deixando de impedir a aglomeração das partículas tão logo a força iônica começa a aumentar. Por outro lado, a estrutura apresentada pelos demais aditivos deve proporcionar uma camada protetora mais espessa na superfície das partículas e portanto menos sensível ao aumento da força iônica.

Dessa forma, a trabalhabilidade de um concreto não pode ser determinada apenas pela cinética de hidratação do ligante, devendo-se considerar o sistema como um todo.

O comportamento de mistura de concretos preparados com o ligante Secar 71 na presença de diferentes aditivos é apresentado na Fig. 4. Com base nestes resultados pode ser observado que somente na presença de ácido cítrico a mistura do concreto foi dificultada elevando-se o nível de torque de virada e o tempo para a completa mistura. $\mathrm{O}$ aditivo $\mathrm{CD}$, assim como para o caso do CA14M, mostrou-se o mais eficiente aliando uma alta fluidez (112\%) com adequada trabalhabilidade (34 min), como apresentado na Fig. 5.

As quedas de trabalhabilidade na presença dos aditivos 
AC, citrato e CS ocorrem pelas mesmas razões discutidas no caso do CA14M uma vez que tais ligantes apresentam o mesmo mecanismo de hidratação. Cabe ressaltar, que na presença de ácido cítrico a aglomeração entre as partículas da matriz é ainda mais acentuada uma vez que ocorre simultaneamente uma queda de $\mathrm{pH}$ do meio, ou seja, o $\mathrm{pH}$ do concreto se desloca de $\sim 10$ para valores próximos de 6 (ponto isoelétrico do sistema matriz-ácido cítrico, Fig. 1). A mistura de um sistema em tais condições exige maiores níveis de torque (Figs. 2 e 4). Além disso, quanto maior a energia de mistura fornecida a uma composição, maior também será a dissipação de calor, gerando aquecimento indesejável ao concreto o que contribui para a redução do tempo de pega.

As curvas de mistura para as composições moldadas utilizando-se como ligante Alphabond 300 na presença de diferentes aditivos dispersantes são apresentadas na Fig. 6. Os resultados quanto a fluidez desses concretos são apresentados na Fig. 7, em comparação com os valores de trabalhabilidade obtidos.

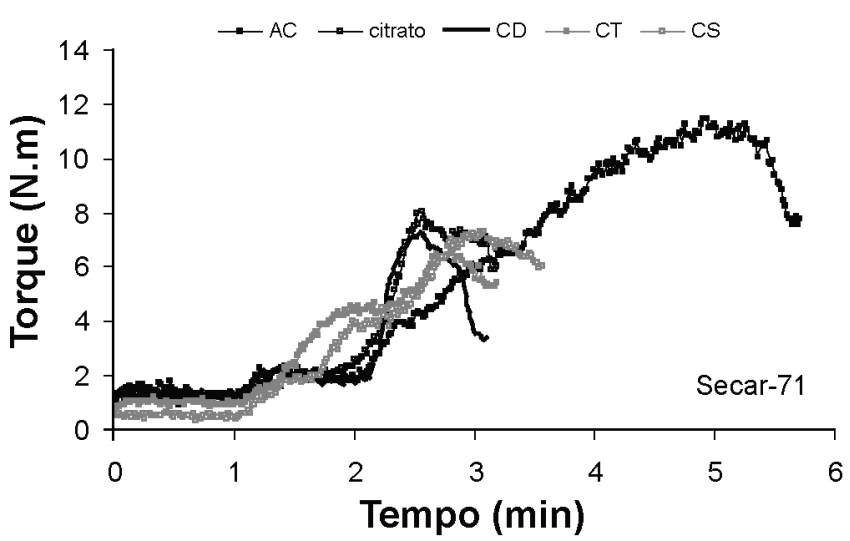

Figura 4: Comportamento de mistura de concretos preparados com Secar-71 na presença de diferentes aditivos dispersantes.

[Figure 4: Mixing curve profiles for the Secar-71 containing castables in the presence of different dispersant additives.]

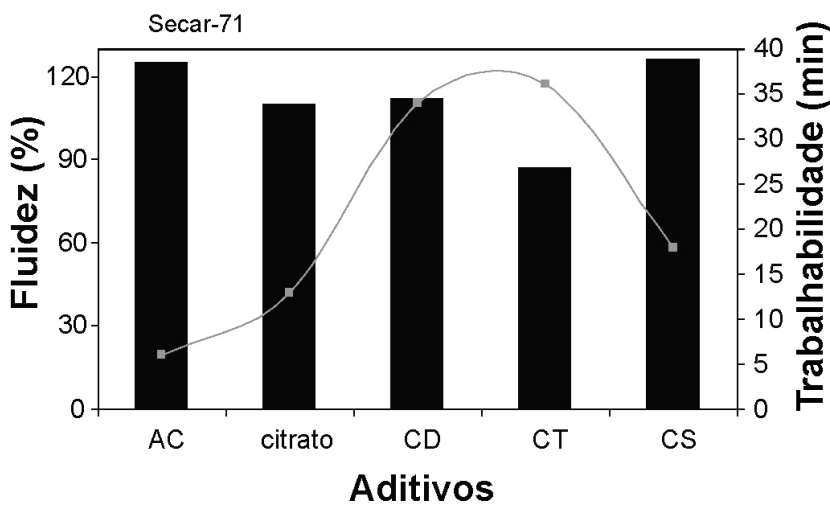

Figura 5: Fluidez e Trabalhabilidade de concretos preparados com Secar-71 na presença de diferentes aditivos dispersantes.

[Figure 5: Fluidity and workability for the Secar-71 containing castables in the presence of different dispersant additives.]
Com base nestes resultados pode ser observado que os aditivos apresentaram comportamentos similares quanto a mistura, apenas diferenciando quanto a solicitação do nível de torque para a virada do concreto sendo menor para os aditivos $\mathrm{CT}$ e CS. O aditivo $\mathrm{CD}$, assim como para o caso do CA14M e Secar-71, mostrou-se o mais eficiente aliando uma alta fluidez (80\%) com alta trabalhabilidade (50 min). Por outro lado, a preparação de concretos utilizando-se Alphabond 300 resultou em composições com menor fluidez as quais consumiram maiores teores de água, quando comparado aos outros ligantes estudados. $\mathrm{O}$ fato das partículas de $\rho$ - alumina apresentarem uma superfície meta-estável e microporosa eleva a área superficial destas aumentando o consumo de água $[5,6]$.

Estudos anteriores também mostraram que a hidratação do Alphabond 300 é sensivelmente retardada na presença dos aditivos ácido cítrico e citrato [9]. O mecanismo de bloqueio da hidratação das partículas de alumina hidratável devido a adsorção das moléculas desses aditivos caracteriza a sua ação retardadora. Por se tratar de moléculas pequenas

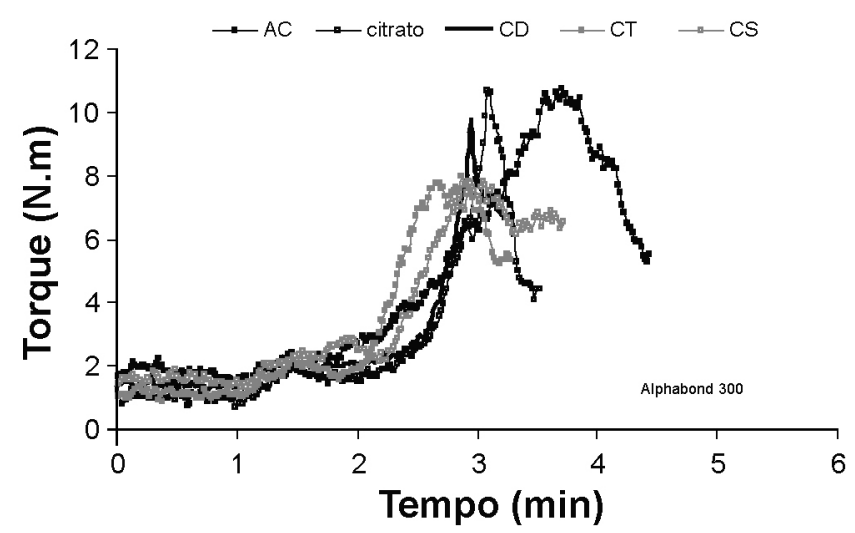

Figura 6: Comportamento de mistura de concretos preparados com Alphabond 300 na presença de diferentes aditivos dispersantes.

[Figure 6: Mixing curve profiles for the Alphabond 300 containing castables in the presence of different dispersant additives.]

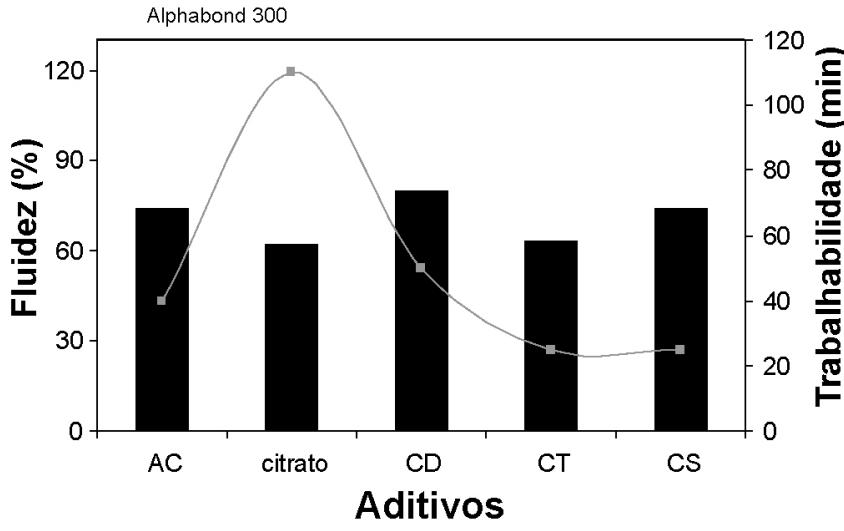

Figura 7: Fluidez e Trabalhabilidade de concretos preparados com Alphabond 300 na presença de diferentes aditivos dispersantes.

[Figure 7: Fluidity and workability for the Alphabond 300 containing castables in the presence of different dispersant additives.] 
deve recobrir mais eficientemente as superfícies quando comparado a adsorção dos demais aditivos. O tempo de pega desse ligante variou de $11 \mathrm{~min}$ para aproximadamente 100 e $200 \mathrm{~min}$ na presença de $0,1 \mathrm{mg} / \mathrm{m}^{2}$ de citrato e ácido cítrico, respectivamente [9]. Isso pode justificar a elevada trabalhabilidade observada na presença de citrato (Fig. 7). $\mathrm{O}$ efeito retardador sobre a pega do concreto (aumento da trabalhabilidade) quando na presença de ácido cítrico deveria se mostrar ainda mais intenso baseando-se no retardamento do mecanismo de hidratação. Entretanto, na presença de ácido cítrico foi verificado redução na trabalhabilidade quando comparada ao citrato a qual pode ser atribuída a queda de $\mathrm{pH}$ promovendo a aglomeração das partículas da matriz.

\section{CONCLUSÕES}

A adequada dispersão do ligante hidráulico, quanto à determinação do tipo e teor de aditivo dispersante, exerce um papel primordial quanto à otimização da fluidez do concreto refratário.

A "pega" inicial do concreto pode ocorrer devido ao efeito direto da formação de fases hidratadas do ligante mas também por efeito indireto causando aglomeração das partículas da matriz. Os aditivos ácido cítrico e citrato, apesar do efeito retardador sobre a precipitação de fases hidratadas, promovem redução da trabalhabilidade do concreto devido a afinidade desses aditivos pelos íons cálcio o que promove um aumento da dissolução das partículas de cimento gerando um aumento da força iônica do meio. $\mathrm{O}$ aumento da força iônica resulta na compressão da dupla camada elétrica das partículas da matriz, reduzindo a repulsão eletrostática entre as mesmas. Este efeito é acentuado devido à formação de uma camada estérica e eletrostática pouco espessa mais susceptível ao aumento da força iônica e a queda de $\mathrm{pH}$ quando na presença de AC.

$\mathrm{Na}$ presença de alumina hidratável ocorre aumento da trabalhabilidade do concreto na presença de citrato devido ao bloqueio da hidratação das partículas causado pela adsorção das suas moléculas. Já na presença de ácido cítrico, apesar do seu significativo efeito retardador da hidratação, a queda de $\mathrm{pH}$ promove aglomeração das partículas da matriz.

\section{AGRADECIMENTOS}

A Almatis e a Lafarge Aluminates pelo fornecimento das matérias-primas e à FAPESP e CNPq pelo suporte financeiro.

\section{REFERÊNCIAS}

[1] T. A. Bier, N. E. Bunt, C. Parr, "Calcium aluminate bonded castables: their advantages and applications", in Proc. The
Latin-American Association of Refractory Manufacturers Meeting, ALAFAR, Buenos Aires, (1996) 75-84.

[2] I. R. Oliveira, A. R. Studart, F. A. Valenzuela, V. C. Pandolfelli, "Influência de aditivos sobre a trabalhabilidade de concretos refratários de ultra-baixo teor de cimento", Cerâmica 49 (2003) 11-16.

[3] K. M. Parker, J. H. Sharp, "Refractory calcium aluminate cements", Trans. J. Brit. Ceram. Soc. 81 (1982) 35-42.

[4] C. M. George, "Aspects of calcium aluminate cement hydration", in Refractories Symposium, The American Ceramic Society, St. Louis, (1994) 1-21.

[5] W. Ma, P. W. Brown, "Mechanisms of reaction of hydratable aluminas", J. Am. Ceram. Soc. 82, 2 (1999) 453456.

[6] Y. Hongo, " $\rho$-Alumina bonded castable refractories", Taikabutsu Overseas 9, 1 (1988) 35-38.

[7] I. R. Oliveira, A. R. Studart, F. A. Valenzuela, V. C. Pandolfelli, "Setting behavior of ultra-low cement refractory castables in the presence of citrate and polymethacrylate salts", J. Eur. Ceram. Soc. 23 (2003) 2225-2235.

[8] I. R. Oliveira, J. R. Garcia, V. C. Pandolfelli, "Influência de aditivos dispersantes e acelerador na hidratação de cimento e cimento-matriz", Cerâmica 52, 323 (2005)184193.

[9] I. R. Oliveira, V. C. Pandolfelli, "Hidratação de ligantes na presença de matriz e aditivos", Cerâmica 53, 327 (2006). [10] I. R. Oliveira, A. R. Studart, R. Pileggi, V. C. Pandolfelli, "Dispersão e empacotamento de partículas - princípios e aplicações em processamento cerâmico", Fazendo Arte Editorial (2000) $195 \mathrm{p}$.

[11] R. G. Pileggi, "Ferramentas para o estudo e desenvolvimento de concretos refratários, Tese de doutorado, UFSCar, S. Carlos, SP (2001) 187p..

[12] R. G. Pileggi, V. C. Pandolfelli, A. E. Paiva, J. Gallo, "Novel rheometer for refractory castables", Am. Ceram. Soc. Bull. 79, 1 (2000) 54-58.

[13] R. G. Pileggi, A. R. Studart, V. C. Pandolfelli, "How mixing affects the rheology of refractory castables. Part I", Am. Ceram. Soc. Bull. 80, 6 (2001) 27-31.

[14] R. G. Pileggi, A. R. Studart, V. C. Pandolfelli, "How mixing affects the rheology of refractory castables. Part II", Am. Ceram. Soc. Bull. 80, 7 (2001) 38-42.

[15] A.R. Studart, W. Zhong, V.C. Pandolfelli, "Rheological Design of zero-cement self-flow castables", Am. Ceram. Soc. Bull. 78, 5 (1999) 65-72.

[16] A. R. Studart, R. Pileggi, V. Pandolfelli, "High-alumina multifunctional refractory castables", Am. Ceram. Soc. Bull. 80, 11 (2001) 34-40.

[17] B. R. Currell, R. Grzeskowlak, H. G. Midgley, J. R. Parsonage, "The acceleration and retardation of set high alumina cement by additives", Cement and Concrete Res. 7 (1987) 420-432.

(Rec. 18/12/2006, Ac. 23/02/2007) 